\title{
Factors Affecting Consumer Awareness and the Purchase of Eco-Friendly Vehicles: Textual Analysis of Korean Market
}

\author{
Naan Ju ${ }^{1}$, Kyu-Hye Lee ${ }^{2}$ (D) and Seong Hun Kim ${ }^{3, *(\mathbb{D}}$ \\ 1 Research Institute of Industrial Science, Hanyang University, Seoul 04763, Korea; naan_ju@hanyang.ac.kr \\ 2 Human-Tech Convergence Program, Department of Clothing and Textiles, Hanyang University, \\ Seoul 04763, Korea; khlee@hanyang.ac.kr \\ 3 Department of Organic and Nano Engineering, Hanyang University, Seoul 04763, Korea \\ * Correspondence: kimsh@hanyang.ac.kr
}

Citation: Ju, N.; Lee, K.-H.; Kim, S.H Factors Affecting Consumer Awareness and the Purchase of Eco-Friendly Vehicles: Textual Analysis of Korean Market. Sustainability 2021, 13, 5566 https://doi.org/10.3390/ su13105566

Academic Editor: Antonio Caggiano

Received: 29 March 2021

Accepted: 11 May 2021

Published: 17 May 2021

Publisher's Note: MDPI stays neutral with regard to jurisdictional claims in published maps and institutional affiliations.

Copyright: (c) 2021 by the authors. Licensee MDPI, Basel, Switzerland. This article is an open access article distributed under the terms and conditions of the Creative Commons Attribution (CC BY) license (https:// creativecommons.org/licenses/by/ $4.0 /)$.

\begin{abstract}
Despite the positive outlook of various organizations on the prevalence of eco-friendly cars, Korea's electric vehicle market is small, and growth is slow. To identify factors that hinder consumer awareness and the spread of eco-friendly vehicles, news articles and online postings on eco-friendly vehicles from 2006 to 2020 were collected and analyzed using text mining techniques. This study found that Korean consumers thought hybrid vehicles were fuel-efficient and quiet; however, there were concerns about battery life and safety due to poor battery performance and complaints about battery replacement. Nevertheless, consumers thought electric cars were sophisticated, luxurious, youthful, clean, and that technical problems would be resolved in the future. The inconveniences of charging and short-distance driving, the expenses and the lack of various dispute settlement measures have been shown to lower the intention to purchase electric vehicles.
\end{abstract}

Keywords: CONCOR analysis; eco-friendly car; opinion mining; topic modeling

\section{Introduction}

Automobiles that use fossil fuel as a power source have caused serious environmental problems by emitting greenhouse gases and harmful exhaust fumes. As the problem of climate change caused by the emission of greenhouse gases becomes more serious and due to the COVID-19 pandemic, global interest in health and safety has increased. The demand for eco-friendly cars using alternative power sources is increasing unprecedentedly. Accordingly, the automobile industry is rapidly changing into an eco-friendly one, and the world's leading automobile companies and many countries are striving to preempt competitiveness in electric cars and new technologies. According to the Ministry of Science, Information and Communications Technology of Korea, the Korean government's goal is for the country to capture $10 \%$ of the global market by producing 3 million electric cars and 850,000 hydrogen cars by 2030 . This would reduce greenhouse gases by an expected $30 \%$ and fine dust by $11 \%$ [1]. However, despite government support and efforts such as subsidies and tax benefits, the market for eco-friendly automobiles has not grown. That said, electric cars are attracting attention as the next-generation eco-friendly vehicles because they drive on batteries and do not emit exhaust and greenhouse gases. According to the International Energy Agency [2], accumulated sales of electric cars worldwide increased to 7.2 million units in 2019 due to regulations in various countries and efforts of automobile manufacturers to protect the environment and $47 \%$ of which were in the People's Republic of China. There are more than 100,000 electric vehicles on the road in 9 countries including China, Canada, France, Germany, Japan, Netherland, Norway, UK, and the USA. And at least 20 countries, electric vehicles have reached market shares above $1 \%$. However, electric cars account for only $1 \%$ of the total number of cars and with $90 \%$ of global electric car sales concentrated in China, Europe, and the United States [2]. Except for Europe, China and the United States, sales of electric vehicles in the rest of the world are quite low. This is due to 
various factors such as lack of government interest in electric vehicles, lack of infrastructure for charging stations, absence of electric vehicles themselves, and cultural differences in means of transportation [3]. Though Korea is one of the world's top five automobile manufacturers, the ranking of electric vehicle sales by country is China first with the highest number of sales, followed by the USA, Norway, Japan, the UK, Germany, France, the Netherlands, Canada, Sweden, and Korea [4]. Currently, the automobile industry is in the process of changing vehicle types from internal combustion engines to electric cars. To drive this change and facilitate the spread of electric cars, research is essential to clarify consumer perceptions of electric cars and the various obstacles that may arise during the adoption of electric cars.

In this study, through the analysis of unstructured big data, we identified consumers' perceptions of and trends in eco-friendly cars and analyzed the market. For this, various types of media and various text analysis methods were used. This involved the examination of general opinion of Korean consumers on the adoption of eco-friendly cars and the present challenges facing countries and major automobile manufacturers worldwide. According to the Markets and markets [5], the electric vehicle market of Asia Pacific is expected to witness the fastest growth, followed by Europe and North America. The automotive industry in the countries such as China, Japan, and South Korea is inclined toward the development of advanced electric vehicles. However, compared to China and Japan, the growth of the electric vehicle market in Korea is slower. Korea's electric car stock is incomparably small compared to that of China, the world's best, and is only a third of Japan's [2]. Our analysis and results show that the automakers and researchers could find it useful to employ unstructured text big data, from newspapers and a web forum, to supplement their survey-based data collection strategies.

\section{Theoretical Background}

\section{Definition and Types of Eco-Friendly Cars}

Eco-friendly vehicles can be defined as vehicles with enhanced capabilities to reduce greenhouse gases or harmful emissions compared to conventional vehicles. These vehicles either save on the use of conventional fossil fuels or use other energy sources to replace fossil fuels [6]. Eco-friendly cars that meet this definition include solar vehicles, hybrid electric vehicles (HEV), plug-in hybrid electric (PHEV), fuel cell electric vehicles (FCEVs), natural gas vehicles, clean diesel vehicles, and battery electric vehicles (BEV) [7]. Ecofriendly cars have a higher entry barrier due to various problems such as poor charging infrastructure and high prices. However, the size of the market for eco-friendly cars is expanding continuously as government-level support plans and ways to activate the spread are proposed in each country. Hydrogen electric vehicles that use hydrogen fuel cells are expected to take longer to enter the market in earnest as the price and stability of the fuel cell stack are yet to be fully verified. Extended range electric vehicles are also slow to distribute in the market. On the other hand, hybrid electric vehicles that generate electricity from internal combustion engines to drive motors, battery electric vehicles powered by pure electricity, and plug-in hybrid electric vehicles equipped with internal combustion engines are evolving rapidly and becoming mainstream in the eco-friendly car market.

A HEV is a vehicle that drives a combination of engine and motor power that charges its battery by generating electricity when the brakes are applied or when going downhill. PHEVs have the same driving system as hybrid vehicles; however, there is a difference in how the car draws and stores energy from external sources. The PHEV is a more advanced vehicle with a larger battery capacity and can be charged with both fuel and electricity. A BEV is a completely pollution-free vehicle [7] that works by supplying electric energy from high voltage batteries to electric motors. BEVs are charged in a low-carbon electricity grid, which makes it possible to reduce greenhouse gas emissions to a very low level [8]. According to Margaritis et al. [9], electric vehicles are characterized by the lightness of the vehicle subsystems such as suspension, steering, and braking and by being equipped with batteries. Also, maintenance costs are 20-30\% lower than internal combustion engines [9]. 
On the other hand, the disadvantage of electric vehicles is that the battery requires to be charged, and for this, separate charging infrastructure is required, and the charging time is long [10]. In terms of consumer behavior, electric cars are an innovation that generates change for the total consumer behavioral stream from selection to usage [11]. For example, since consumers are unfamiliar with electric vehicles and do not have a lot of purchasing experience, so it takes a lot of time and effort to make a purchase decision. Also, to use an electric vehicle, the driver must be used to connecting the vehicle to the electric grid, charging the battery while not in use, and planning the next ride in advance [12]. According to $\mathrm{Ju}$ [13], consumers usually reluctant to change, so innovations that demand change aren't always welcomed by consumers. This study aims to identify consumers' perception of eco-friendly cars and the factors that affect consumers' intention to purchase these vehicles, focusing on hybrid cars that include plug-in hybrids and electric cars, the mainstream options in the eco-friendly car market. According to Oliver and Rosen [14], environmental value is a strong predictor of American consumer's behaviors and positively effects on willingness to act to protect the environment. For instance, Heffner et al. [15] found that consumers who showed a high level of environmental awareness in purchasing were more likely to buy eco-friendly cars than those who were less concerned about the environment. Similarly, Gallagher and Muhlegger [16] found that social preferences for the environment are the main determinant of consumer environmentally friendly automotive adoption. In research on electric vehicles, many studies have shown that there is a correlation between the eco-friendly lifestyle [17], eco-friendly attitude [18], interest in the environment [19], and the intention to purchase electric vehicles.

On the other hand, McDonald's et al. [20] argue that some environmentally oriented consumers can continue to purchase products that can harm the environment (e.g., flying or air travel). The properties of electric vehicles also affect consumer preferences for them. Numerous studies conducted on consumers in various countries such as USA [17], Netherlands [21], Denmark [22], and Sweden [23] show that the high purchase cost of electric vehicles negatively affects their preference. Insufficient charging infrastructure [24], short mileage due to lack of battery technology [25], and long charging time [24] are also considered major barriers to the adoption of electric vehicles. On the other hand, according to Jensen et al. [22], low fuel and operating costs have a positive impact on consumer preference for electric vehicles. In addition, government support such as tax concessions and subsidies and a well-established infrastructure have a positive impact on electric vehicle preference [24].

According to McKinsey \& Company [26], global auto sales decreased during the COVID-19 crisis; however, the electric vehicle market is far more likely to see a quick recovery. Although Korea is one of the world's top five automobile manufacturers, the market share of electric cars in Korea is only 2\% [4]. Despite various government support efforts, including subsidies, tax incentives, and the construction of charging stations, the expansion of the eco-friendly automobile market in Korea is slowing down. According to Rezvani et al. [27], expanding the electric vehicle market requires an understanding of what psychological mechanisms are required for promoting the purchase and acceptance of electric vehicles, in addition to the characteristics and demographic effects of electric vehicles themselves. Graham-Rowe et al. [28] also suggest that the consumers' psychological aspects are required to be studied extensively, as they could affect purchases.

In this study, opinion mining was used to identify consumer awareness of electric and hybrid vehicles and factors affecting the purchase and acceptance of these eco-friendly vehicles. Opinion mining is mainly applied to analyze public opinion on products and services preferences, social events, and political issues from various social media content [29]. Among the various techniques used in big data analysis, opinion mining is important for not only individuals but also companies. Individuals may want to see other customers' opinion of a product before buying it. Companies seek to analyze customer feedback to improve the features of their product and make future decisions. 


\section{Method}

\subsection{Data Collection}

Text analysis is conducted to better understand public opinion about the benefits and obstacles of adopting eco-friendly vehicles. Newspaper articles and posts on web forums have been selected as two relevant sources for examination. To extract the main topics discussed on eco-friendly cars in Korean media, a newspaper corpus was generated and topic modeling was conducted. The newspaper articles were extracted using a Korean media database (bigkinds). This database contains 54 news brands, encompassing major/minor news brands and general/specific news coverage. In this study, news articles published in the Chosun Ilbo, JoongAng Ilbo, Dong-A Ilbo, Maeil Business News Korea, The Hankyoreh, Kyunghyang Shinmun, and The Digital Times were analyzed as targets in consideration of the number of sales units and awareness. The search term used to extract these articles was "green car," "eco-friendly car," "electric car," and "hybrid car" in Korean. The articles were extracted over the last 15-year period (1 January 2006 to 31 December 2020) and in total 155,589 articles were analyzed.

An analysis of the annual number of news reports related to eco-friendly cars shows that the number of reports began to increase rapidly from 2008 and increased further until 2010 (Figure 1). Most of the news articles at this time were about Hyundai Motor Company's first plug-in hybrid car and its policy to cut the vehicle acquisition registration tax on electric vehicles. However, from 2010 to 2012, articles about eco-friendly cars declined. In line with the timing of mass production of electric vehicles by GM, Nissan, and BYD, governments of each country also announced support plans that would attract attention, such as subsidies, exemption from various taxes, and discounts on parking lots. However, since 2011, when electric vehicles began to be mass-produced in earnest, the sales performance of electric vehicles in the world was far below expectations [30]. As the global economic recession enters a prolonged phase, the high price of electric vehicles has undermined consumers' willingness to buy. These chilly reactions from consumers affected automakers' new car development strategies, and governments' policies to promote ecofriendly vehicles have also begun to confuse. The situation in Korea was no different. Global electric vehicles were not even imported at all, and there were many articles that the full-scale launch of electric vehicles developed by domestic companies was imminent, but it was not easy to see electric vehicles in operation around us. In 2012, Hyundai Motor Company and Kia Motors Corporation launched their Sonata and K5 hybrid models, and related articles and eco-friendly car sales increased significantly. Since then, with the production of second-generation electric vehicles in 2016, news reports related to electric vehicles have increased significantly, and overall news related to eco-friendly cars has exploded.

The second sample analyzed was extracted from a popular online community for car enthusiasts, Bobaedream.co.kr (accessed on 3 May 2021). With more than 1 million members and an average of 1.7 million visitors per month, Bobaedream.co.kr is the largest online community in Korea and the 15th largest in the world [31]. The data collected using a Python-based crawler made for this study using BeautifulSoup. A web crawler is a program that can repeatedly and automatically download web pages and extract and fetch the necessary information from HTML [32]. To extract web data, DOM (Document Object Model) based methods [33] were used. BeautifulSoup is a Python data extraction library developed by Leonard Richardson and other open-source developers. It can parse HTML and XML documents and provides simple methods to interact with the DOM model.

A total of 24,239 cases from March 2006 to December 2020, when the first solarpowered hybrid electric vehicle in Korea entered a pilot phase and posts on electric vehicles began to appear. We searched for posts using the search terms "green car," "eco-friendly car," "electric car," and "hybrid car" in Korean. 


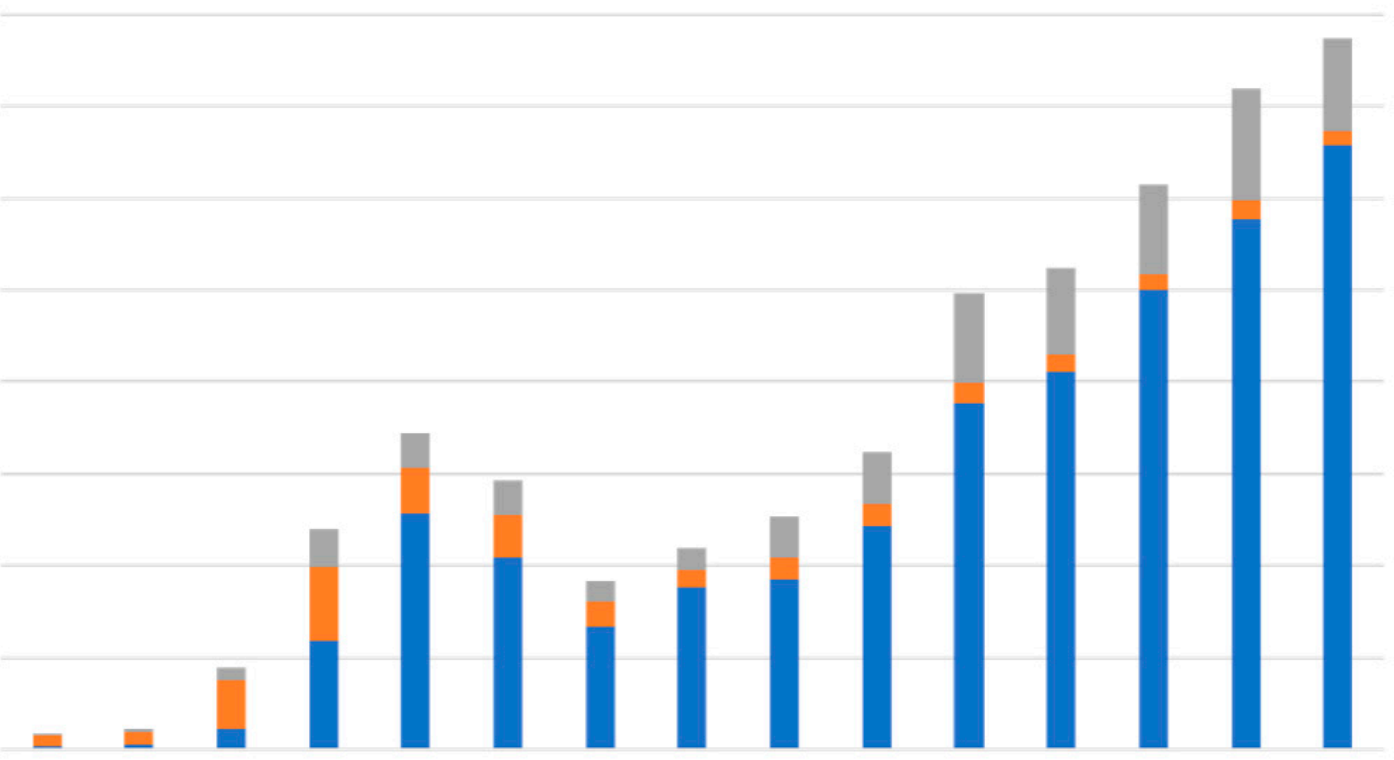

200620072008200920102011201220132014201520162017201820192020

\section{Electric Cars mybrid Cars Eco-friendly Cars}

Figure 1. Number of news reports related to eco-friendly vehicles by year.

\subsection{Analysis Techniques}

Content analysis allows people to review the meaning or key ideas of a message. In this study, NLTK (natural language toolkit), Konlpy (Korean NLP in Python), and Mecab-ko packages, a Korean text analysis software package were used to extract the co-occurrence matrix of frequently used terms. NLTK packages are useful for investigating the frequency of occurrence of specific terms as well as the degree of combinations and combinations of specific words. In addition, semantic network analysis, a type of social network analysis, was performed to analyze posts, where the basic unit of analysis is the term. Social network analysis can be useful for describing the units and their relationships expressed in social network structure and for analyzing conflicts.

Ahead of the main process, the text data underwent basic text processing, that is, tokenization, stop words removal, and lemmatization. This preprocessing aimed to eliminate words, symbols, or characters that are not important for extracting information. The second process was to remove stop words, that is, words that are likely insignificant for information extraction, such as conjunctions (e.g., "for" and "but") and articles (e.g., "the" and "a"). In this research, 283 words were considered as stop words and included 47 slang words. The last text processing task performed by researchers was lemmatization, which allows various forms of a word to group and analyze them into a common base form. Without this step, the model views these words as distinct entities and reduces the overall importance in the entire model. This pre-processing of the posts was carried out using the Konlpy and Mecab-ko packages in Python. After cleaning and preprocessing, all text documents were combined to create a corpus [34]. These packages allowed us to conduct tagging for 44 Korean language part of speech (POS). In contrast to the newspaper article, user-generated content requires further pre-processing since the data typically contain numerous abbreviations, emoticons, slang words, and misspellings [35].

To run a mathematical model on a text corpus, the corpus was transformed into a document term matrix representation. Using Python's Gensim library, a document term matrix was prepared and an LDA model was executed. Latent topic models are effective 
methods for extracting latent semantic information from text corpora, and LDA (Latent Dirichlet Allocation) appears to be the most effective one. LDA models assume that a document is a distribution over a topic and the topic is represented as the distribution over the word [36]. As a result, topic modeling assumes that each document can contain multiple topics, so documents are not grouped together. Instead, by linking documents and topics, it is possible what topics are distributed for each document, or how topics are distributed in what documents, and how words reveal topics. This research implemented LDA as inference process for document-level classification task.

To reveal hidden subgroups and investigate the semantic structure of the text, convergence of iterated corrections (CONCOR) analysis was performed [37]. CONCOR analysis is a method that performs a correlation analysis repeatedly to identify appropriate levels of similarity in groups. The CONCOR analysis can distinguish more meaningful subgroups in a network where the relationship of keywords is relatively clear, making it easier to diagnose similarities with correlations. These derived subgroups or structural isostatic groups are called "blocks," and additional analyses can be performed on these blocks to elicit implications. Therefore, CONCOR analysis is sometimes called "block modeling." The CONCOR analysis identifies individual blocks that correspond to a set of highly correlated keywords, while also identifying relationships between blocks [38]. For semantic network analysis, CONCOR analysis was performed using UCINET, a social network analysis tool. Employing CONCOR, we classified the messages on the two types of eco-friendly cars into several categories and analyzed the text. UCINET was used to visualize the network.

\section{Result}

In the second half of 2016, according to the LG Economic Research Institute [39], the emergence of second-generation electric vehicles with a range of more than $300 \mathrm{~km}$ made it possible for electric cars to compete directly with cars with an internal combustion engine. Therefore, in this study, we compared and analyzed posts written between March 2006 and June 2016, when posts were written about the development of eco-friendly cars, with posts written between July 2016 and December 2020, after the appearance of the second generation of electric cars, to see if there were any changes in the perception and attitude toward eco-friendly cars.

\subsection{Text Analysis Finding 1: Issue Networks over Time}

Word clouds are widely used to summarize and visualize the content and themes of a text. Word clouds utilize a variety of font sizes and colors to display important words in a text. They are effective to visually summarize the main contents of the text and to intuitively guiding the users to navigate the theme of the text.

Figure 2 illustrates the 30 most frequently encountered nouns in the dataset. It provides a general overview of the dominant terms related to the topic of eco-friendly cars in news articles. In the early days of eco-friendly car development, there were many articles that emphasized the environment-friendly nature of these vehicles, particularly electric and hybrid cars. Many articles focused on the development of new fuel vehicles and new cars that would be unveiled at motor shows. On the other hand, as eco-friendly cars began to be mass-produced, there were more articles on how Korean companies could play a role in the global market. As companies such as LG Chemistry, SK Innovation, and Samsung SDI produced batteries for electric vehicles, words such as "batteries," "future," and "development" were ranked at the top, and there were many comments about these companies. Meanwhile, in the early stage of eco-friendly car development, hybrid cars were mentioned a lot; however, as the development of eco-friendly vehicles is actively progressing, after July 2016, the hybrid cars were mentioned less frequently (5th $\rightarrow 77$ th), and the words 'hydrogen,' 'Tesla,' and 'future' have emerged. This can be interpreted as a result of the emergence of cars that match the elements of eco-friendly cars more than hybrid vehicles, and hybrid vehicles are perceived as economical cars of 'fuel efficiency' and 'appropriate price' rather than 'eco-friendly'. Words such as "Hyundai Motor Com- 
pany," "China," "investment," and "factory" also showed that Korea was focusing on the development and production of future eco-friendly cars, including electric vehicles.
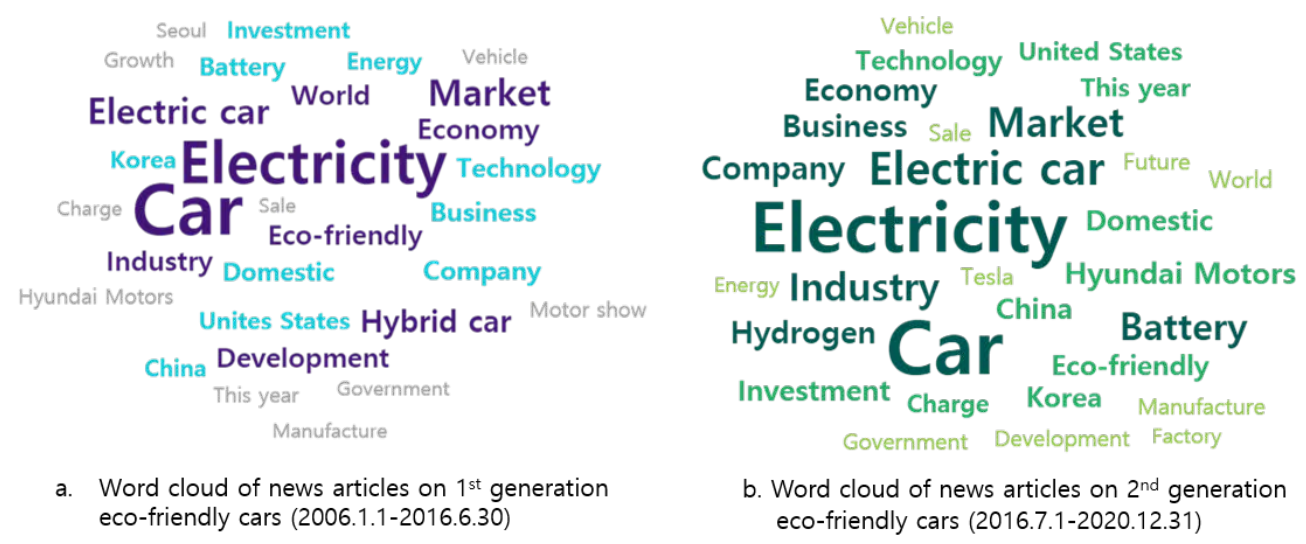

Figure 2. Word clouds of nouns used in the news article on eco-friendly cars.

LDA algorithms were used to extract topics from news articles. The clustered topics were first named by one researcher based on the identification of a logical connection between the most frequently occurring words for a topic. Then this topic name was confirmed by a second researcher who was not otherwise involved in the project. Table 1 shows the results of topic modeling. To tokenize and clean the texts, such as by removing stopwords such as "things" and "stuff" from the inquiry and combining words with the same base (e.g., "drive" and "driving"). Looking at the topics in the news related to eco-friendly vehicles by period, the following search terms appeared most frequently in the first period: "government policy," "technology development," "new vehicle launch trends," "domestic industry related to an eco-friendly car," and "battery." In the second period, the terms were: "government policy," "technology development and investment," "eco-friendly car market," and "new vehicle launch trends." Looking at the changes in topics by period, "government policy" appeared in both the first and second generations. The focus of the first period was on government regulations and government support or benefits to encourage the purchase of eco-friendly vehicles, whereas in the second period, the focus was on the green industry, including the eco-friendly automobile business, which was seen as a national task of the government, and on the process of promoting it, new jobs, and services. It was based on the content of the "Green New Deal." Topics on battery development, investment in EVs, and the export of EVs appeared in both the first and second periods. In particular, the Korean government and companies thought the electric vehicle battery industry was very important, and as a result of sustained investment and development, many companies, including SK Innovation, Samsung SDI, and LG Chemistry, have now gained an important position in the market.

\subsection{Text Analysis Finding 2: Opinion Mining of Electric Cars}

The dominant terms related to electric cars in online postings are shown in Figure 3. The top 30 words were compared according to frequency of use in each period and divided into the first generation from March 2006 to June 2016 and the second generation from July 2016 to December 2020. Words such as "hybrid," "development," "fuel efficiency," and "performance" topped the list in the early stages of electric vehicle development, while words such as "hydrogen," "design," "problem," "Tesla," "China," and "stock" appeared in the second generation. 
Table 1. Topics for each period.

\begin{tabular}{|c|c|c|}
\hline Period & Topic & Word \\
\hline \multirow{5}{*}{$01 / 01 / 2006-06 / 30 / 2016$} & $\begin{array}{l}\text { Government } \\
\text { policy }\end{array}$ & $\begin{array}{l}\text { Car, government, sale, domestic, subsidy, } \\
\text { diesel, market, support, industry, Japan, } \\
\text { counter plan, standard, import, price, this year, } \\
\text { last year, regulation, hybrid car, economy, } \\
\text { outlook }\end{array}$ \\
\hline & $\begin{array}{l}\text { Technology } \\
\text { development }\end{array}$ & $\begin{array}{l}\text { Electricity, car, eco-friendly, hybrid car, electric } \\
\text { car, vehicle, charge, development, Hyundai } \\
\text { Motor Company, release, hydrogen, driving, } \\
\text { automatic driving, technology, model, } \\
\text { domestic, Ioniq, supply, Kia Motors } \\
\text { Corporation, Seoul }\end{array}$ \\
\hline & New vehicle launch trends & $\begin{array}{l}\text { Car, Tesla, market, United States, world, motor } \\
\text { show, model, Korea, local, China, company, } \\
\text { international, release, time, Busan, this year, } \\
\text { sale, Hyundai Motor Company, domestic, } \\
\text { global }\end{array}$ \\
\hline & $\begin{array}{c}\text { Domestic } \\
\text { industry related to eco-friendly cars }\end{array}$ & $\begin{array}{l}\text { Industry, energy, economy, investment, } \\
\text { company, business, technology, growth, } \\
\text { market, future, electricity, LG, field, Gwangju, } \\
\text { smart, innovation, development, Korea, } \\
\text { strategy, stock price }\end{array}$ \\
\hline & Battery & $\begin{array}{l}\text { Electricity, electric car, battery, car, China, LG, } \\
\text { chemistry, business, manufacture, company, } \\
\text { charge, Samsung SDI, SK innovation, supply, } \\
\text { factory, market, development, conclusion, } \\
\text { innovation, Jeju Island }\end{array}$ \\
\hline \multirow{4}{*}{$07 / 01 / 2016-12 / 31 / 2020$} & $\begin{array}{l}\text { Government } \\
\text { policy }\end{array}$ & $\begin{array}{l}\text { Industry, economy, government, company, } \\
\text { New Deal, president, energy, support, policy, } \\
\text { region, environment, eco-friendly, business, car, } \\
\text { future, carbon, job, Korea, propulsion, Biden }\end{array}$ \\
\hline & $\begin{array}{c}\text { Technology } \\
\text { development and investment }\end{array}$ & $\begin{array}{l}\text { Battery, business, electricity, electric car, } \\
\text { company, technology, development, factory, } \\
\text { chemistry, China, manufacture, investment, } \\
\text { automotive parts, future, car, material, market, } \\
\text { charge, mobility, supply }\end{array}$ \\
\hline & Eco-friendly car market & $\begin{array}{l}\text { Tesla, COVID-19, United States, market, } \\
\text { quarter, stock price, investment, domestic, car, } \\
\text { this year, chemical, Korea, performance, export, } \\
\text { stock market, outlook, contrast, sale, record, } \\
\text { economy }\end{array}$ \\
\hline & New vehicle launch trends & $\begin{array}{l}\text { Car, electricity, Hyundai Motor Company, } \\
\text { hydrogen, electric car, vehicle, Kia Motors } \\
\text { Corporation, eco-friendly, release, model, } \\
\text { brand, domestic, market, sale, unveil, this year, } \\
\text { charge, Korea, world }\end{array}$ \\
\hline
\end{tabular}



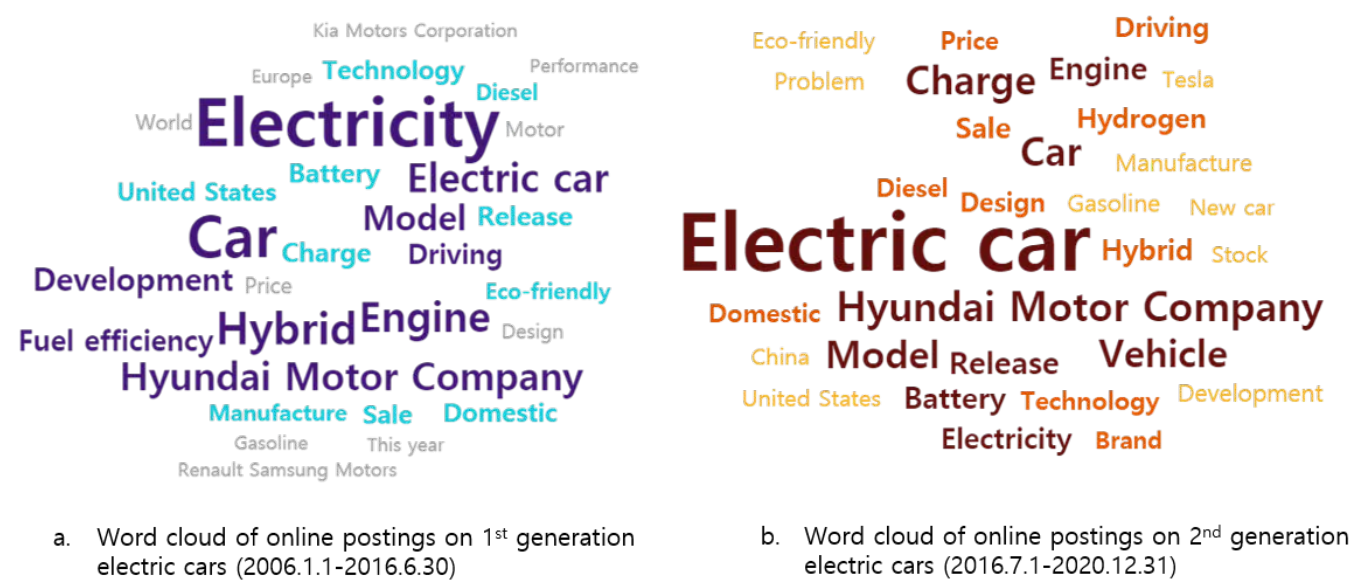

Figure 3. Word clouds of nouns used in the online postings on electric cars.

Looking at the countries that were mentioned frequently in the posts during each period, "Europe" and "United States" were mentioned a lot in the first period; however, "China" ranked 27th in the second period as the Chinese electric vehicle market developed rapidly under the leadership of the state. On the other hand, the rankings of the USA and Europe fell. The word "charge" was mentioned much more in the second generation than in the first generation, and the words "distance" and "problem" confirmed the increased interest and dissatisfaction with charging issues as the use of electric vehicles spread. Meanwhile, as electric cars became popular in the second generation, words such as "stock," and "stock price" appeared.

Using COCOR analysis, texts from both periods were classified and analyzed into several categories. The results of the CONCOR analysis provided four themes based on word frequently (Figures 4 and 5).

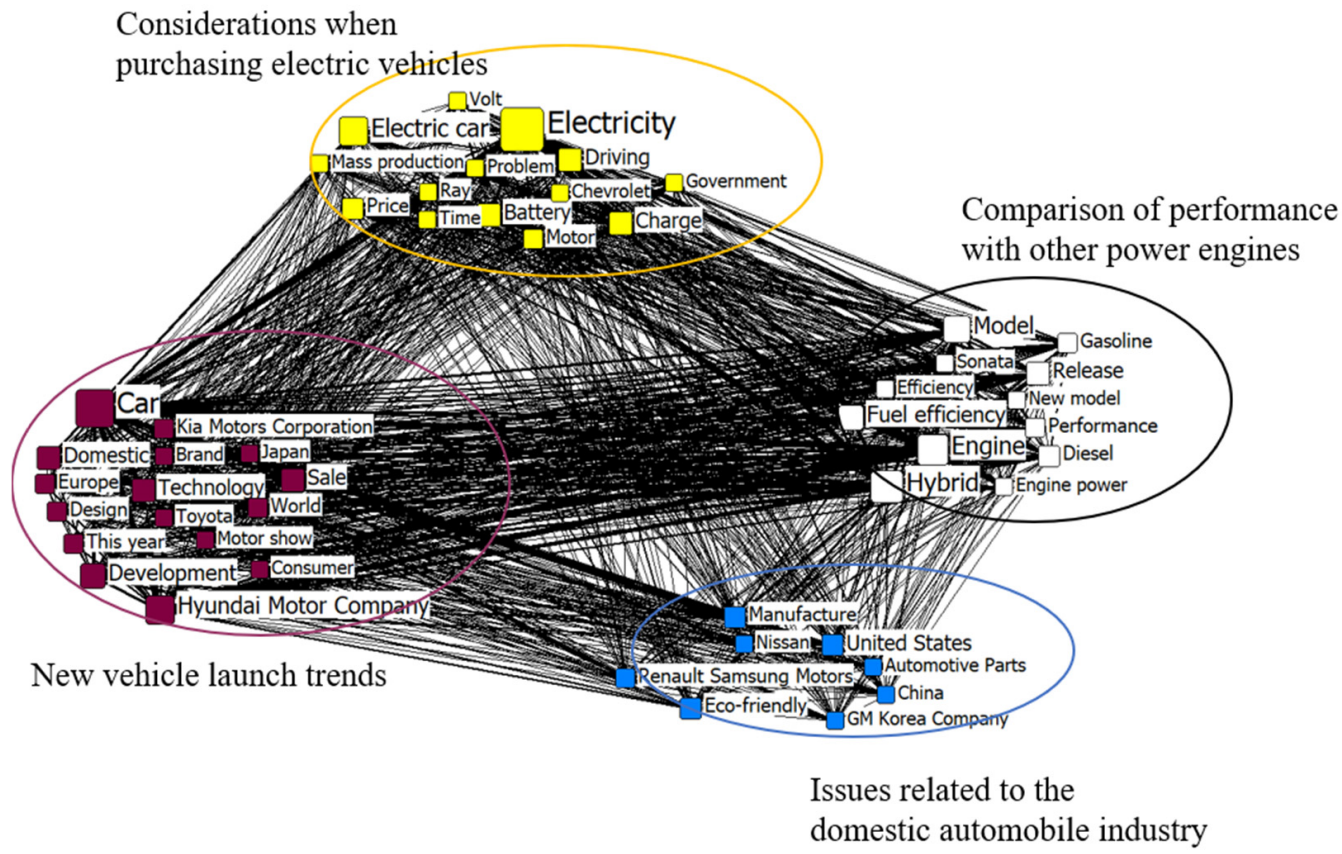

Figure 4. Visualization of CONCOR analysis: Texts on 1st generation of electric cars. 


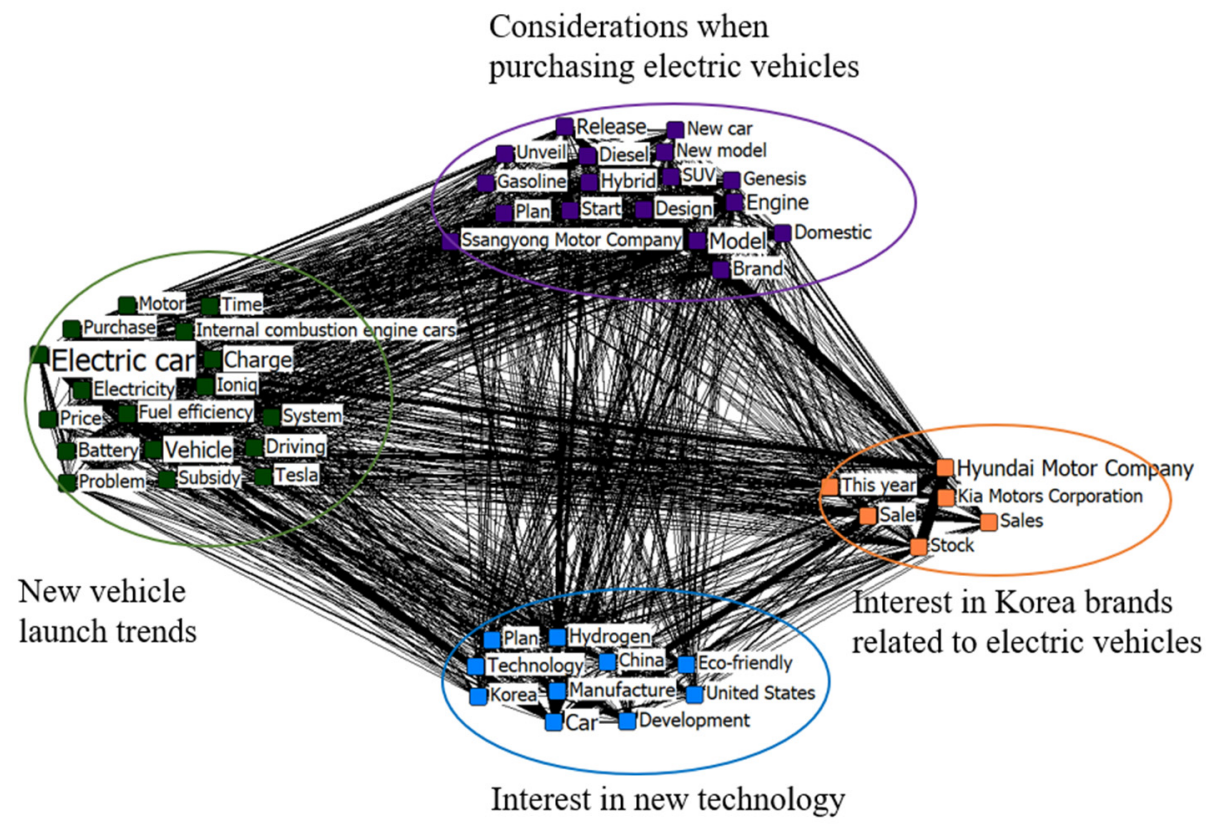

Figure 5. Visualization of CONCOR analysis: Texts on 2nd generation of electric cars.

The first generation's four themes of electric cars are listed by the frequency of the key words: "new vehicle launch trends," "considerations when purchasing electric vehicles," "comparison of performance with other power engines," and "issues related to the domestic automobile industry (Figure 4)." The most frequently mentioned topic in postings on firstgeneration of electric vehicles was the launch of new vehicles. Words such as "Japan," "Toyota," "Europe," "motor show," "brand," "Hyundai Motor Company," "Kia Motors Corporation," and "design" showed a lot of interest in electric cars emerging from various brands. Comments on Japan, which led the development of the first electric vehicles, and Europe, which created the electric vehicle market with strong regulations, showed that these countries played an important role in the early electric vehicle market. On the other hand, through words such as "battery," "price," "problem," "motor," "charge," and "time", the factors that consumers consider when purchasing electric vehicles are different from those of conventional internal combustion locomotives. In the same context, words such as "diesel," "gasoline," "hybrid," "engine power," "efficiency," "performance," and "engine" indicated that consumers had started to compare electric vehicles with other power-engine vehicles in terms of attributes. In addition, there were also comments on issues concerning the auto industry, such as Renault Samsung's strike and GM's withdrawal from Korea.

The second generation's four themes of electric cars ranked in order of the frequency of key words are: "interest in the release of new cars," "considerations when purchasing electric vehicles," "interest in new technology," and "interest in domestic electric vehicle manufacturers (Figure 5)."

After the launch of the second-generation electric car, consumers continued to pay attention to the launch of new car. In the second-generation electric vehicle, as the popularity of electric vehicles progresses, a hybrid vehicle or a popular model among existing internal combustion locomotives is released as an electric vehicle, or an electric vehicle with improved performance and design is released. As luxury car manufacturers such as BMW, Jaguar, and Mercedes-Benz launched electric vehicles and various lines of electric vehicles from sports cars to SUVs to suit the consumer's lifestyle were developed, consumers' interest in electric vehicles has increased continued. As both electric and hybrid cars were popularized, the second generation specifically mentions SUV electric vehicles and SUV hybrid cars among various types of cars, which can be interpreted as the popularity of SUVs in the Korean market and around the world. In Korea, SUVs are popular for their practicality and excellent safety. And recently car campers who would like to modify their 
cars so they can sleep in them while camping are increasing rapidly due to the COVID-19 pandemic. Next, words such as "subsidy," "system," "Tesla," "price," and "fuel efficiency" showed that consumers were more actively considering purchasing electric vehicles than before. Consumers were interested in how much the subsidies would make electric cars cheaper and various consumers are considering buying high-end electric vehicle brands such as Tesla. BMW, Meanwhile, as the development of electric vehicles progressed, online posts are started to mention "China," "Korea," and the "USA," which are countries leading the electric vehicle market and production. Interest in hydrogen cars, a new technology related to eco-friendly cars, also emerged. In this regard, interest in Korea's "Hyundai Motor Company," which focuses on the electric vehicle and hydrogen car market segment, also increased. Many consumers were interested in the growing eco-friendly car market and the issue of developing a platform exclusively for electric vehicles, even if they were not planning to purchase eco-friendly cars themselves. This is a result of reflecting the growing interest of domestic consumers in eco-friendly vehicles such as hybrid, electric and hydrogen vehicles [40].

According to the Figure 6, words related to positive emotions included "new," "high performance," "high class," "improvement," "expectation," "innovative," "benefit," "excellent," "success," "dramatically," and "clean." In other words, consumers were optimistic about improvements in electric vehicles in the future and saw electric vehicles are sophisticated and luxurious following the introduction of electric vehicles by luxury automotive brands such as BMW, Tesla, Mercedes Benz, Audi, and Jaguar. The words "innovative," and "clean" also showed that purchasing an electric vehicle could create a positive image.

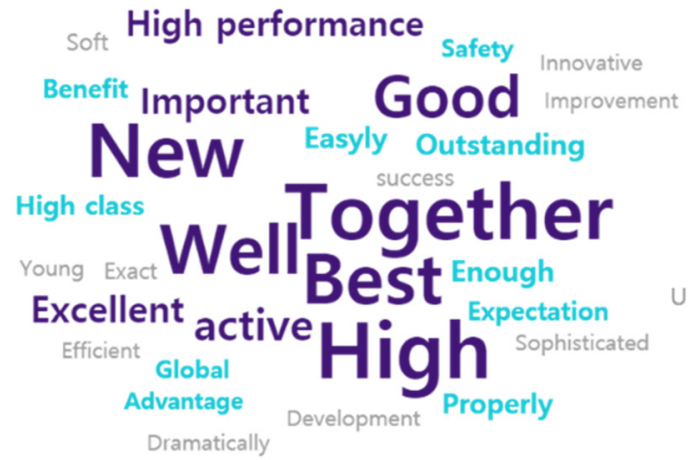

a. Positive emotion related to Electric car

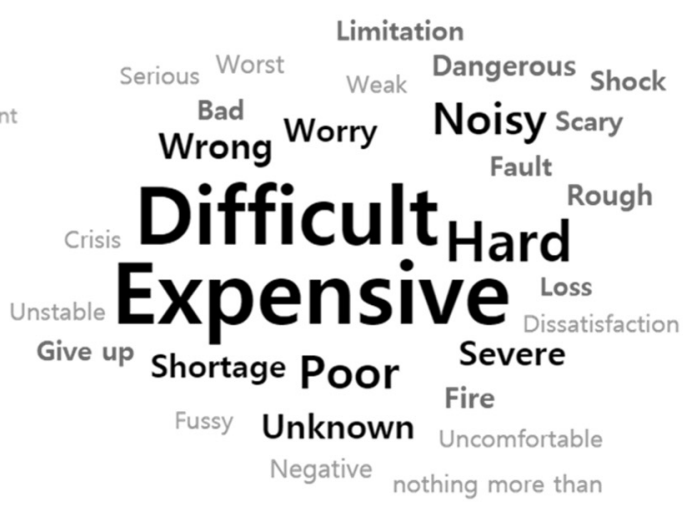

b. Negative emotion related to Electric car

Figure 6. Word clouds of the emotions extracted from the online postings on electric cars.

Negative emotion words related to electric vehicles included "fire," "expensive," "poor," "worried," "noisy," "serious," "uncomfortable," "difficult," and "defective." Because of fire accidents, the most common word related to negative emotions was "fire." In the case of "expensive," it was not only associated with the price of the vehicle but also with "repair cost," indicating that difficulty in repairing cars or the high cost of the repairs were major obstacles to the acceptance of electric vehicles. Meanwhile, words related to "lack" appeared, such as "technology," "option," "knowledge," "safety," "mileage," "infrastructure," "charging station," "power," and "bill," indicating that there was anxiety about the manufacturing. The analysis also found that it was essential to prepare standards for punishment for obstruction to charge and the checking of charging facilities for the spread of electric vehicles. In addition, there was a lack of options to choose from, and there was also an anxiety about the lack of electric vehicle maintenance experts.

\subsection{Text Analysis Finding 3: Opinion Mining on Hybrid Cars}

As a result of extracting and comparing the 30 most frequently mentioned words in postings related to hybrid cars before and after July 2016 in the early days of the hybrid 
car launch, words such as "fuel economy," "price," "development," "performance," and "motor" appeared (Figure 7). However, as development progressed and various hybrid cars were introduced, the words "new," "concerned," "option," and "selection" became popular. Through this, we found that consumers increasingly considered buying hybrid cars.
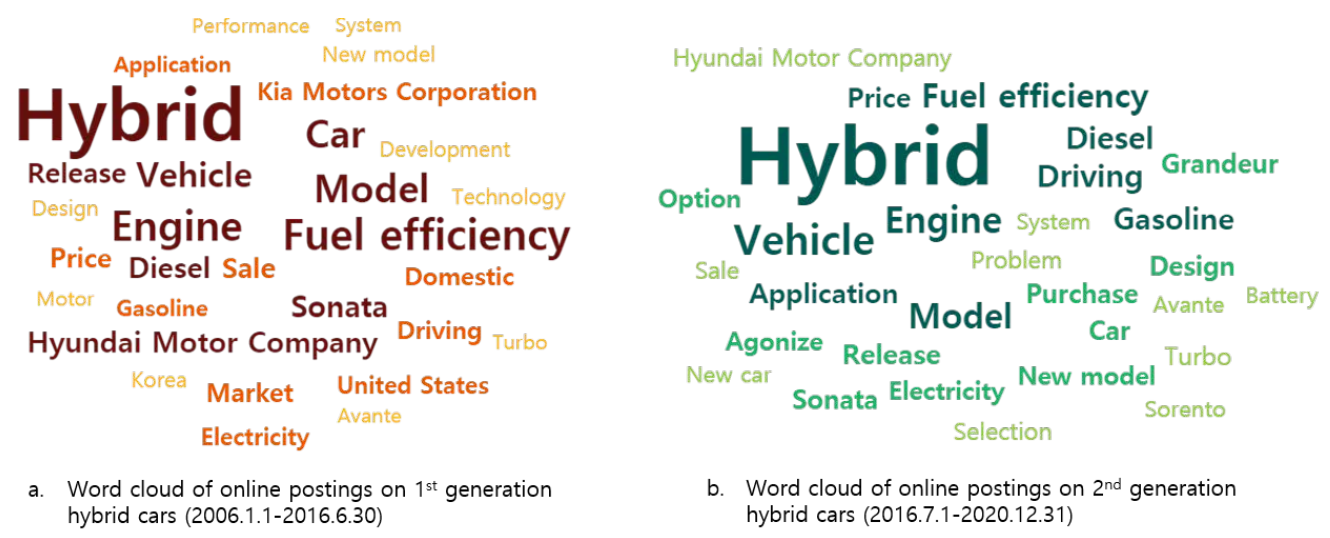

Figure 7. Word clouds of nouns used in the online postings on hybrid cars.

In Figure 8, the four themes of the first generation are ranked in order of the volume of key words: "performance of hybrid vehicles," "new vehicle launch trends," "considerations when purchasing electric vehicles," and "leading countries and companies in electric vehicles."

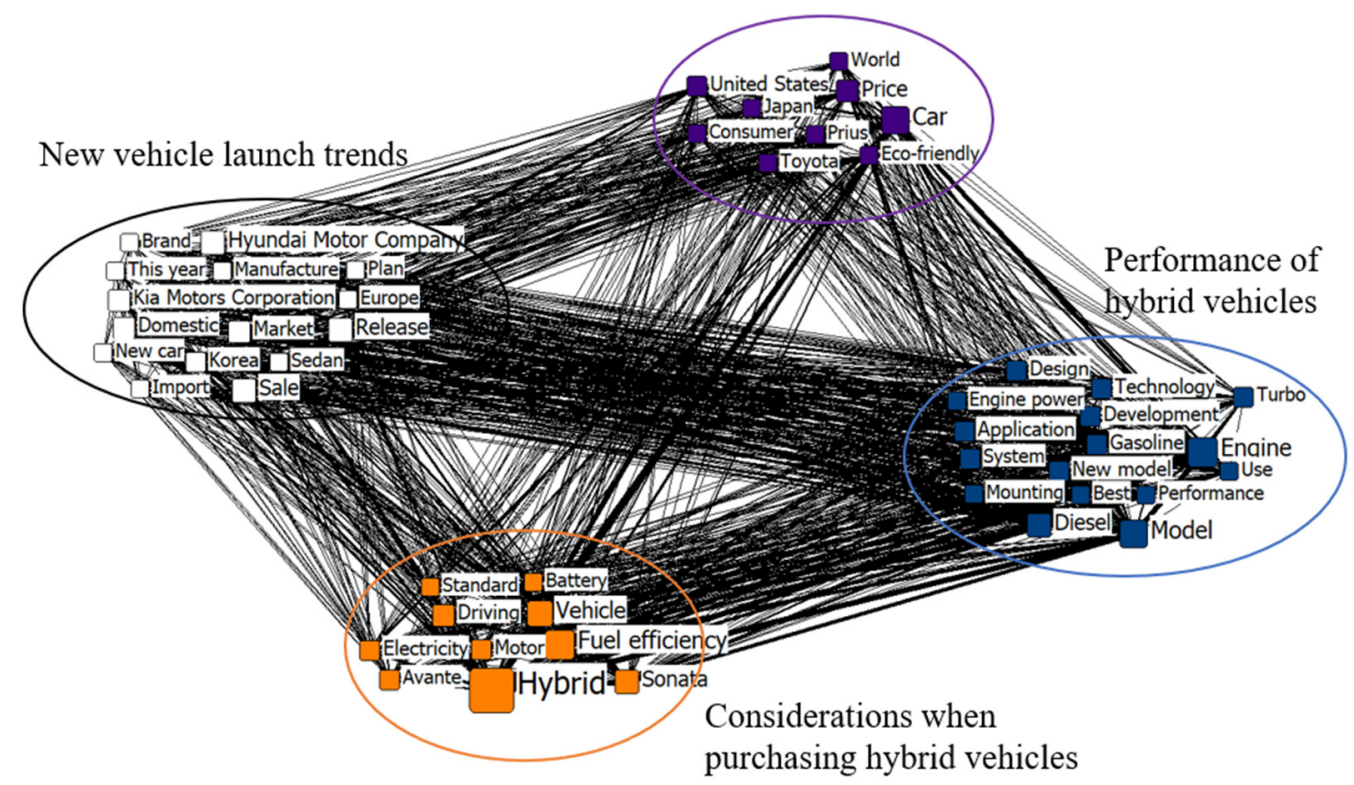

Figure 8. Visualization of CONCOR analysis: Texts on 1st generation of hybrid cars.

First, words such as "engine power," "performance," "best," "design," "mounting," "application," "system," "use," "technology," and "turbo" show that consumers are interested in the performance and construction of hybrid cars. Words such as "plan," "this year," "release," and "new car," show that the nature of the automobile-related community, there were many posts about newly released hybrid cars. Additionally, words such as "Sonata," "Avante," "fuel efficiency," "battery," and "electricity" indicate that the comparison criteria with internal combustion engines are fuel economy, battery performance, and electricity usage. "Sonata" and "Avante" are among the best-selling cars in Korea and they are usually the standard for Korean consumers when they compare prices and performance when purchasing vehicles. Words such as "Toyota," "Prius," "Japan," and the "USA" indicated the leading companies and countries in the early hybrid market. 
In Figure 9, the four themes of the second generation are ranked in order of the volume of key words: "specific performance of hybrid vehicles," "new vehicle launch trends," "considerations when purchasing electric vehicles," and "intention to purchase."

Considerations when purchasing hybrid vehicles

Specific performance of

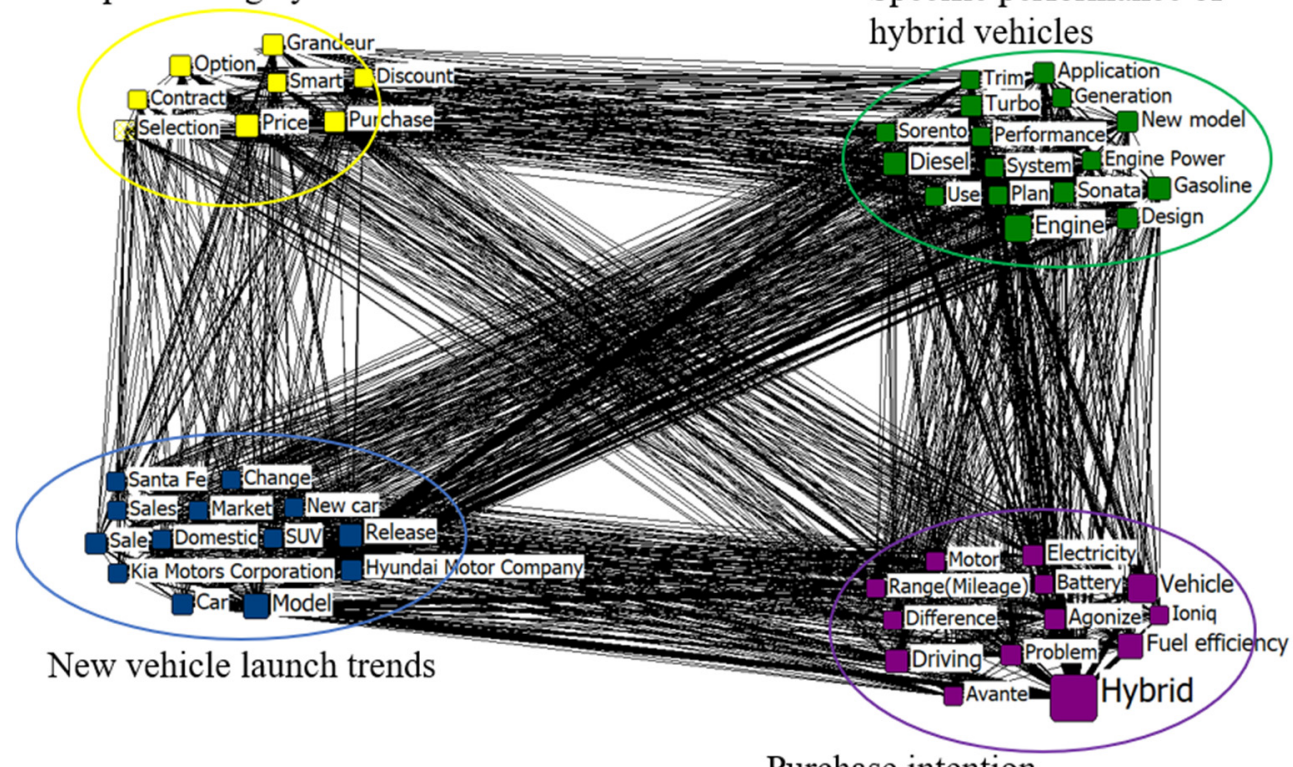

Purchase intention

Figure 9. Visualization of CONCOR analysis: Texts on 2nd generation of hybrid cars.

Looking at the words in the "specific performance of hybrid vehicles" group, consumer interest has shifted from a broader interest in hybrid vehicles to more specific vehicle models and options. Words like "trim", "application," "generation," "new model," "design," "Sonata," and "Sorento" confirmed this. This consumer's tangible interest can also be confirmed through the mention of specific car brands such as "Santafe," "Ioniq," "Avante," and "Grandeur". The words "difference," "range," "mileage," "problem," "concern," "battery," "option," "discount," "contract," and "selection" also indicated that many consumers had purchased or were considering purchasing a hybrid car.

Positive emotion words related to hybrid vehicles included "new," "high performance," "outstanding," "easily," "high class," "steadily," "popularity," "like," "prefer," "optimal," and "reasonable (Figure 10)." Through these words, we found that consumer thought hybrid cars not only excelled in performance but were also highly fuel efficient and convenient as new innovative products. Negative emotion words related to hybrid vehicles included "defect," "faulty," "nuisance," "damage," "stress," and "burden."

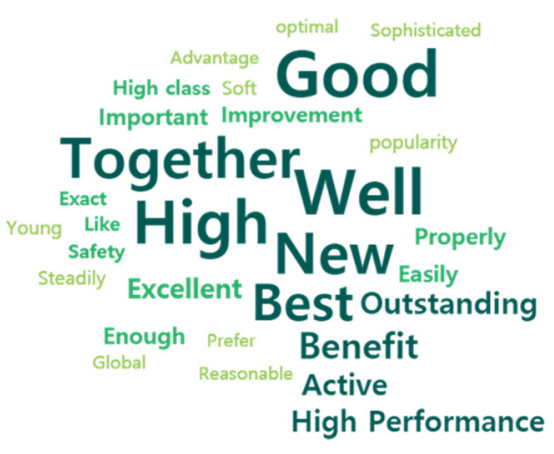

a. Positive emotion related to Hybrid car

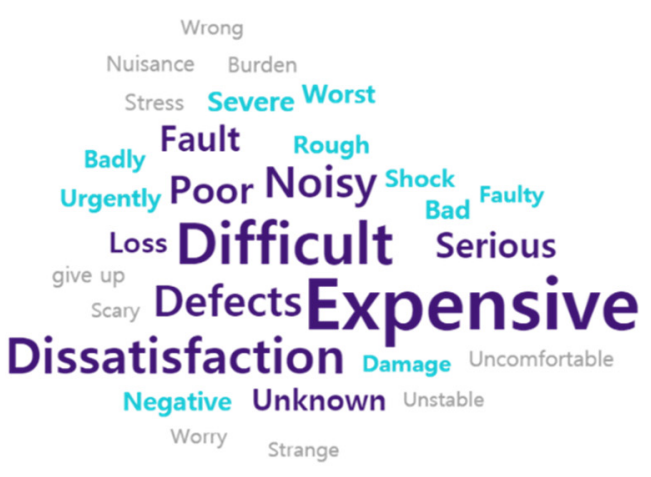

b. Negative emotion related to Hybrid car

Figure 10. Word clouds of the emotion extracted from the online postings on hybrid cars. 


\section{Discussion}

To examine public opinion on the adoption of eco-friendly cars and current challenges facing countries and major automobile manufacturers, we used two types of text data: news articles and online postings. Through topic modeling, CONCOR analysis, and sentiment analysis algorithms, we found patterns in the text data.

The study found that consumers thought hybrid vehicles were fuel-efficient, quiet, and were satisfied with the benefits of discounts. The positive words related to hybrid cars, included "popularity," "like," and "prefer" showed the hybrid cars are more popular compared to electric cars. Many specific car names were also mentioned in the posts related to the hybrid car, indicating that consumers were buying hybrid cars more frequently than electric vehicles. On the other hand, there were concerns about battery life, fuel efficiency, and safety problems due to poor battery performance, and complaints about battery replacement. Meanwhile, in the news related to eco-friendly cars, mentions of hybrid cars also declined as cars that emphasized eco-friendliness were developed, such as 'hydrogen electric cars' and 'electric cars'. As hybrid cars became popular, consumers considered specific properties such as design and trim, in addition to fuel efficiency and performance.

Consumers thought electric cars were sophisticated, luxurious, and clean, and expected the problems they had today to be improved in the future. Also, positive words related to electric cars, included "expected," "success," and "innovative." This showed that electric cars are more innovative than hybrid cars, requiring more behavioral changes from consumers. Interest in electric vehicles was initially comprehensive, including interest in Japanese brands leading the electric vehicle market and a small number of brands unveiled through motor shows, vehicle prices, driving methods, charging time, and types of mass-production cars. With the increase in popularity of electric vehicles, consumers' postings changed to specific levels of interest, such as the development of third-generation electric vehicles with im-proved performance, electric vehicles versus hybrid vehicles, autonomous driving, and $500 \mathrm{~km}$ on a single charge. However, the inconvenience of charging, short-range (mileage), expensive prices, and lack of options to solve various issues related to owning electric vehicles remain as factors that lower consumer acceptance of electric vehicles. Furthermore, a series of recent electric car fires left consumers questioning the stability of electric vehicles, which had a significant negative impact on their intention to purchase them.

\section{Conclusions}

\subsection{Study Theoretical and Practical Implications}

This study analyzed factors that affect consumer recognition and purchase of electric and hybrid cars in automotive web forums using big data analysis technology. Big data analysis can be used not only to analyze individual behaviors, consumer choices, and emotions but also to predict the near future through various pattern analyses. The results are significant in that the study has been able to identify various factors that have not been revealed in previous studies. For example, factors such as anxiety about incomplete technology, lack of regulation on electric vehicle charging disturbing behavior, expensive repair costs, difficulty in repair due to the lack of electric vehicle maintenance experts, and lack of rescue and towing experts who understand the characteristics of electric vehicles were found to have a negative influence on the acceptance and spread of eco-friendly vehicles.

As consumers' interest in eco-friendly cars is increasing and consumers considering actual purchases are increasing, manufacturers and governments can promote the spread of eco-friendly cars if they make the following efforts based on the results of this study.First, automakers need to think about how to convince consumers to buy their electric vehicles. The most obvious way to do this is to first keep current customers' brand loyalty when switching from an internal combustion engine to an electric car or encourage new customers to choose their own brand or product when purchasing an electric car. To achieve either (or both), automakers need to re-establish a consumer segmentation strategy that targets customers to their behavior and needs. According to the results of a survey of 
consumers in the UK, consumer behaviors and attitudes depend on respondents' age, monthly consumption level, and vehicle ownership. This also affected the usage and average mileage of the car to be purchased later [40]. In addition, since battery charging, mileage, and stability issues were pointed out as problems, that automakers should develop their product proceed with a focus on these areas.

In addition, according to this study, consumers were aware of various problems such as the management of chargers at electric vehicle charging stations, the lack of proper regulations to discourage interfering with charging electric vehicles, and the occurrence of disputes due to stealing electricity. Therefore, the government must come up with specific and practical solutions to various social problems that may arise in the process of innovation, as well as future technical problems. Also, according to Deloitte's global automative consumer study [40], 37\% of Korean consumers say they don't want to pay more to purchase electric vehicles that have similar performance to conventional internal combustion locomotives. Therefore, subsidies and tax benefits to encourage the purchase of electric vehicles will continue to be needed for the time being.

\subsection{Study Limitations and Future Research}

Despite the wide appeal of Bobaedream.co.kr (accessed on 3 May 2021), it should be borne in mind that comments may not be representative of the Korean population. In addition, the limitation of this study is that only certain newspapers were included in the analysis, considering the newspaper's circulation and awareness. In the future, if research is conducted to analyze news articles from various countries at the same time, it will be possible to understand the differences in social perceptions and policies on eco-friendly vehicles by country. Furthermore, based on the results of this study, quantitative research will be required in the future to identify factors that affect the awareness and intention to purchase eco-friendly cars by millennials, who will be the main players in the future automobile market. In addition, this study has limitations in that it was only targeting Korean consumers. In the future, if a study is conducted to find out the perceptions of electric vehicles by consumers in three European countries (Norway, Sweden, and the Netherlands) with a high share of electric vehicles through text mining methods, it is expected to be a study that can further contribute to the spread of electric vehicles.

Author Contributions: Conceptualization, N.J. and S.H.K.; methodology, N.J.; software, N.J.; validation, N.J., S.H.K. and K.-H.L.; formal analysis, N.J.; investigation, N.J., S.H.K. and K.-H.L.; resources, N.J.; data curation, N.J.; writing—original draft preparation, N.J.; writing—review and editing, S.H.K. and K.-H.L.; visualization, N.J.; supervision, S.H.K.; project administration, S.H.K.; funding acquisition, S.H.K. All authors have read and agreed to the published version of the manuscript.

Funding: This research was supported by Basic Science Research Program through the National Research Foundation of Korea (NRF) funded by the Ministry of Education (NRF-2016R1A6A1A03013422).

Institutional Review Board Statement: Not applicable.

Informed Consent Statement: Not applicable.

Data Availability Statement: All data generated or analyzed during this study are included in this article.

Conflicts of Interest: The authors declare no conflict of interest.

\section{References}

1. Ministry of Science, Information and Communications Technology. Available online: https://www.korea.kr/news/ pressReleaseView.do?newsId=156355724\&call_from=rsslink (accessed on 11 November 2020).

2. International Energy Agency 2020. Available online: https://www.iea.org/reports/global-ev-outlook-2020 (accessed on 3 May 2021).

3. Deloitte. Available online: https://www2.deloitte.com/us/en/insights/focus/future-of-mobility/electric-vehicle-trends-20 30.html (accessed on 5 May 2021).

4. International Energy Agency 2019. Available online: https://www.iea.org/reports/global-ev-outlook-2019 (accessed on 23 December 2020). 
5. Markets and Markets. Available online: https://www.marketsandmarkets.com/Market-Reports/electric-vehicle-market-209371 461.html (accessed on 7 May 2021).

6. KEITI. Available online: https://www.konetic.or.kr/include/EUN_download.asp?str=WEBZINE.dbo.TBL_REPORT\&str2=2346 (accessed on 10 December 2020).

7. Eco Car. Available online: https://www.ev.or.kr/portal/ecocar (accessed on 10 January 2021).

8. White, L.V.; Sintov, N.D. You are what you drive: Environmentalist and social innovator symbolism drives electric vehicle adoption intentions. Transport. Res. A Pol. 2017, 99, 94-113. [CrossRef]

9. Margaritis, D.; Anagnostopoulou, A.; Tromaras, A.; Boile, M. Electric commercial vehicles: Practical perspectives and future research directions. Res. Transp. Bus. Manag. 2016, 18, 4-10. [CrossRef]

10. Zhang, Y.; Qian, Z.S.; Sprei, F.; Li, B. The impact of car specifications, prices and incentives for battery electric vehicles in Norway: Choices of heterogeneous consumers. Transp. Res. Part C Emerg. Technol. 2016, 69, 386-401. [CrossRef]

11. Taylor, M.; Fujita, K. Available online: https:/ / escholarship.org/uc/item/4hj203w3 (accessed on 3 May 2021).

12. Axsen, J.; TyreeHageman, J.; Lentz, A. Lifestyle practices and pro-environmental technology. Ecol. Econ. 2012, 82, 64-74. [CrossRef]

13. Ju, N.; Lee, K.-H. Consumer resistance to innovation: Smart clothing. Fash. Text. 2020, 7. [CrossRef]

14. Oliver, J.D.; Rosen, D.E. Applying the environmental propensity framework: A segmented approach to hybrid electric vehicle marketing strategies. J. Mark. Theory Pract. 2010, 18, 377-393. [CrossRef]

15. Heffner, R.R.; Kurani, K.S.; Turrentine, T.S. Symbolism in California's early market for hybrid electric vehicles. Transp. Res. D Transp. Environ. 2007, 12, 396-413. [CrossRef]

16. Gallagher, K.S.; Muehlegger, E. Giving green to get green? Incentives and consumer adoption of hybrid vehicle technology. J. Environ. Econ. Manag. 2011, 61, 1-15. [CrossRef]

17. Hidrue, M.K.; Parsons, G.R.; Kempton, W.; Gardner, M.P. Willingness to pay for electric vehicles and their attributes. Resour. Energy Econ. 2011, 33, 686-705. [CrossRef]

18. Carley, S.; Krause, R.M.; Lane, B.W.; Graham, J.D. Intent to purchase a plug-in electric vehicle: A survey of early impressions in large US cites. Transp. Res. D Transp. Environ. 2013, 18, 39-45. [CrossRef]

19. Sang, Y.N.; Bekhet, H.A. Modelling electric vehicle usage intentions: An empirical study in Malaysia. J. Clean. Prod. 2015, 92, 75-83. [CrossRef]

20. McDonald, S.; Oates, C.; Thyne, M.; Timmis, A.; Carlie, C. Flying in the face of environmental concern: Why green consumers continue to fly. J. Mark. Manag. 2015, 31, 1503-1528. [CrossRef]

21. Bockarjova, M.; Steg, L. Can protection motivation theory predict pro-environmental behavior? Explaining the adoption of electric vehicles in the Netherlands. Glob. Environ. Chang. 2014, 28, 276-288. [CrossRef]

22. Jensen, A.F.; Cherchi, E.; Mabit, S.L. On the stability of preferences and attitudes before and after experiencing an electric vehicle. Transp. Res. D Transp. Environ. 2013, 25, 24-32. [CrossRef]

23. Chowdhury, M.; Salam, K.; Tay, R. Consumer preferences and policy implications for the green car market. Market. Intell. Pln. 2016, 34, 810-827. [CrossRef]

24. Liao, F.; Molin, E.; Van Wee, B. Consumer preferences for electric vehicles: A literature review. Transp. Rev. 2017, 37, 252-275. [CrossRef]

25. Degirmenci, K.; Breitner, M.H. Consumer purchase intentions for electric vehicles: Is green more important than price and range? Transp. Res. D Transp. Environ. 2017, 51, 250-260. [CrossRef]

26. McKinsey \& Company. Available online: https://www.mckinsey.com/industries/automotive-and-assembly/our-insights/ electric-mobility-after-the-crisis-why-an-auto-slowdown-wont-hurt-ev-demand (accessed on 11 December 2020).

27. Rezvani, Z.; Jansson, J.; Bodin, J. Advances in consumer electric vehicle adoption research: A review and research agenda. Transp. Res. D Transp. Environ. 2015, 34, 122-136. [CrossRef]

28. Graham-Rowe, E.; Gardner, B.; Abraham, C.; Skippon, S.; Dittmar, H.; Hutchins, R.; Stannard, J. Mainstream consumers driving plug-in battery-electric and plug-in hybrid electric cars: A qualitative analysis of responses and evaluations. Transp. Res. D Transp. Environ. 2012, 46, 140-153. [CrossRef]

29. Chen, H.; Zimbra, D. AI and opinion mining. IEEE Intell. Syst. 2010, 25, 74-80. [CrossRef]

30. Gtm. Available online: https://www.greentechmedia.com/articles/read/does-it-matter-how-many-evs-will-be-on-the-roadby-2015 (accessed on 7 May 2021).

31. Similarweb. Available online: https://www.similarweb.com/ (accessed on 18 September 2020).

32. Chengcheng, W. Data information crawler technology based on Python. Electron. World 2018, 11, $208-209$.

33. Álvarez-Sabucedo, L.M.; Anido-Rifón, L.E.; Santos-Gago, J.M. Reusing web contents: A DOM approach. Softw. Pract. Exper. 2009, 39, 299-314. [CrossRef]

34. Manning, C.D.; Raghavan, P.; Schütze, H. Introduction to Information Retrieval; Cambridge University Press: Cambridge, UK, 2008; Volume 19, pp. 1041-4347.

35. Kumar, S.; Morstatter, F.; Liu, H. Twitter Data Analytics; Springer: New York, NY, USA, 2013.

36. Blei, D.M.; Ng, A.Y.; Jordan, M.I. Latent dirichlet allocation. J. Mach. Learn. Res. 2003, 3, 993-1022.

37. Cho, S.E.; Choi, M.G.; Park, H.W. Government-civic group conflicts and communication strategies: A text analysis of TV debates on Korea's Import of US Beef. J. Contemp. East. Asia. 2012, 11, 1-20. [CrossRef] 
38. Chung, W.J.; Kim, D.W.; Yoon, H.Y.; Lee, H.M.; Park, J.W.; Kim, D.S.; Shon, Y.K.; Cheon, H.S.; Cheon, Y.S.; Jung, Y.M.; et al. Big Data Research Methods and Applications; Hakjisa: Seoul, Korea, 2019.

39. LG Economic Research Institute. Available online: http://www.lgeri.com/report/view.do?idx=19519 (accessed on 16 October 2020).

40. Deloitte. Available online: https://www2.deloitte.com/content/dam/Deloitte/us/Documents/manufacturing/us-2020-globalautomotive-consumer-study-global-focus-countries.pdf (accessed on 7 May 2021). 